\title{
Direct and indirect economic impacts of drought in the agri-food sector in the Ebro River basin (Spain)
}

\author{
M. Gil, A. Garrido, and N. Hernández-Mora \\ CEIGRAM, Technical University of Madrid, c/ Senda del Rey 13, 28040 Madrid, Spain \\ Correspondence to: M. Gil (marina.gil@upm.es) \\ Received: 14 December 2012 - Published in Nat. Hazards Earth Syst. Sci. Discuss.: - \\ Revised: 30 June 2013 - Accepted: 9 July 2013 - Published: 28 October 2013
}

\begin{abstract}
The economic evaluation of drought impacts is essential in order to define efficient and sustainable management and mitigation strategies. The aim of this study is to evaluate the economic impacts of a drought event on the agricultural sector and measure how they are transmitted from primary production to industrial output and related employment. We fit econometric models to determine the magnitude of the economic loss attributable to water storage. The direct impacts of drought on agricultural productivity are measured through a direct attribution model. Indirect impacts on agricultural employment and the agri-food industry are evaluated through a nested indirect attribution model. The transmission of water scarcity effects from agricultural production to macroeconomic variables is measured through chained elasticities. The models allow for differentiating the impacts deriving from water scarcity from other sources of economic losses. Results show that the importance of drought impacts are less relevant at the macroeconomic level, but are more significant for those activities directly dependent on water abstractions and precipitation. From a management perspective, implications of these findings are important to develop effective mitigation strategies to reduce drought risk exposure.
\end{abstract}

\section{Introduction}

Droughts originate from a deficiency in precipitation that, if sustained over time, may result in water shortages for human consumption, economic activities or environmental requirements (Wilhite and Glantz, 1985). The special characteristics of droughts, such as their slow temporal onset and uncertain spatial propagation, set droughts apart from other natural hazards and make impacts difficult to assess (Wilhite, 1993). These characteristics require innovative methodologies to evaluate the economic impact and scope of a drought (Wipfler et al., 2009).

Water-dependent activities such as agricultural production, agri-food industry and agricultural employment are severely impacted by a reduction in water availability. Irrigated agriculture is the main consumptive water user in Spain, using up to $90 \%$ of available water resources in the Ebro River basin (CHE-SDMP, 2007). Irrigated agriculture is therefore particularly vulnerable to drought hazards. Rainfed agriculture is also vulnerable to droughts, but has a lower exposure because of lower land productivity and lower agricultural production value. Both irrigated and rainfed agriculture provide the primary inputs for the agri-food industry, and drought impacts are therefore transmitted from one to another. Wilhite et al. (2007) and Iglesias et al. (2007) highlight the complexity of assessing drought impacts that spread over time into many sectors of the economy. It is therefore important to develop methodologies that allow for the measurement of the losses directly and indirectly attributable to water shortages; to discriminate these impacts from other influencing variables; and to describe how these losses are related to one another. Garrido et al. (2010) and Gil et al. (2011) contributed to this work by developing econometric models that assess the impacts of drought on agricultural production. Their approach is adapted and further developed in this paper to measure the magnitude of the impacts and their spread throughout the economy.

An accurate assessment of the socioeconomic and environmental impacts of drought is necessary to enable improved management of water as a scarce natural resource, inform water allocation decisions in times of drought and 
design adequate drought mitigation and prevention measures that help minimize impacts. Recent focus on the need to improve the assessment of the costs of natural hazards in general, and droughts in particular, responds to concerns about the increased risks that derive from expected climate change processes. As a result, for example, recent EU-funded initiatives, such as the Xerochore (2010) and ConHaz projects (Logar and van den Bergh, 2013), have emphasized the need to improve the quality and reliability of drought impact assessments. Basin-wide studies that integrate economic and hydrologic optimization models have been used to assess different policy alternatives in order to minimize impacts. According to Ding et al. (2011) most drought impact studies are developed for a specific drought event, contributing to assessment improvement for policy makers. Nonetheless, a greater emphasis is needed to assess the real scope and spread of drought damages from primary to industrial sectors and isolate these effects from other sources of economic performance variations (such as price variations).

\section{Evaluation methods of economic drought impacts}

The economic performance of a specific sector in times of drought is influenced by many factors, not only water availability. In order to discriminate the impacts of drought from other influencing variables we can develop econometric models that include relevant explanatory variables of the event and measure the causal relation and the attribution effect between variables (Martínez-Cachá, 2004). The use of econometric models as a tool to evaluate the impacts of drought at different levels would have the advantage of discriminating drought effects from others. Furthermore, it allows us to obtain production elasticities with respect to water availability, and the related effects across sectors (from primary sector to agri-food industry and agricultural employment).

Water is an important input for agricultural production, and therefore variations in the amount of water affect agricultural production levels, although the variation is not necessarily proportional. The elasticity between these two variables determines the magnitude of the impact that will occur. In turn, the elasticity between agricultural production and related macroeconomic variables completes the chain of causation, offering an inferential device to analyse impacts in the economy caused by water supply shocks.

Most of the analyses concerning the elasticity of water as a production input evaluate the price elasticity of water demand, with the price or shadow price being the variable factor. Schoengold et al. (2006) measure the direct effects of water pricing on water demand, and the indirect effects on changes in crop choices or irrigation technology, using the concept of elasticity. However, regardless of variations in water prices, water use variations also generate different indirect impacts that can be evaluated. In this paper, the direct and indirect economic effects of water supply on agriculture are evaluated. Decaluwe et al. (1999) argue that introducing water price elasticity in analytical models permits evaluating policy alternatives considering welfare criteria and water conservation objectives. While this may be true, droughts result in reductions in production as a result of the decrease in water availability that outweigh potential crop price increases. The result is an overall decrease in the value of agricultural production. The elasticity of water can also be used to calculate how these decreases are transmitted from variables directly affected by water to indirectly affected economic variables.

The economic impacts of drought and its spreading and repercussions throughout the economy of a region occur through economic links between the markets of primary products, whose production relies on water availability, and the economic activities that process them. The simpler direct estimations of drought losses measure the physical damage to crops (Ritcher and Semenov, 2005; Hartman, 2003; Xiao-jun et al., 2012), and the microeconomic estimations of these damages, relating market prices to production functions (Klein and Kulshreshtha, 1989), are the natural extension of the evaluation of primary production impacts. A number of studies analysing the economic impact of droughts use mathematical programming models to simulate economic impact using linear (Dono and Mazzapicchio, 2010; Peck and Adams, 2010) and non-linear models (Jenkins et al., 2003; Booker et al., 2005). Hydro-economic models also combine mathematical programming with socio-economic and environmental aspects to measure drought risks (Ward and Pulido-Velázquez, 2012). Econometric models fitted at the macroeconomic level (Alcalá Agulló and Sancho Portero, 2002; Martínez-Cachá, 2004) or at the level of the irrigation district (Lorite et al., 2007), the irrigated farm (Rubio Calvo et al., 2006) or single crops (Quiroga and Iglesias, 2009) were also developed for this purpose. Other authors have used computable general equilibrium models (CGE) or input-output (IO) models to study the regional effects of water scarcity (Goodman, 2000; Gómez et al., 2004; Berrittella et al., 2007; Pérez y Pérez and Barreiro-Hurlé, 2009). Welfare losses of drought are also assessed by some authors, using choice experiments (Martin-Ortega and Berbel, 2010) or other innovative methods, such as happiness evaluations (Carroll et al., 2009; Frey et al., 2009).

Moreover, complete estimations of drought losses have been recently accomplished by some authors. Martín-Ortega et al. (2012) performed this kind of study for the city of Barcelona, and, detailed compilations of existing literature were made by Ding et al. (2011) or Logar and van den Bergh (2013), who agreed on the low impact of droughts over the total GDP of a region, and also on the need to have more accurate estimations.

Evaluations of direct and indirect impacts of drought have often been made through IO models. The importance of these models rests on the calculation of indirect impacts, but the 
magnitude of direct losses is generally estimated by simple comparison between the economic output of a specific sector in drought years with that of previous non-drought years. This attribution may be inaccurate without considering time trends or other factors influencing economic results. IO models use the direct impact as the starting point of analysis to derive the indirect impacts through forward and backward economic linkages. This approach assumes that negative effects provoked by changes in final demand will transfer via a multiplying effect to production and employment in the economic structure of the region (Leontief, 1986). Therefore, if the effect on production is incorrectly measured none of the other relations would be precise.

IO tables are highly specific for the economy of a particular geographical area. In Spain Pérez y Pérez and BarreiroHurlé (2009) use this approach to evaluate the economy of the Ebro River basin, and Chóliz et al. (2009) model the economic importance of water within the economy of the Aragón autonomous community ${ }^{1}$ (located in the Ebro Basin) by using the Social Accounting Matrix and Environmental Accounts (SAMEA). Morilla et al. (2007) use IO models to measure the efficiency of industrial water uses, but they suggest the methodology could imprecisely estimate the multiplier effect, which may increase the estimation of impacts as they are transmitted. Therefore, IO analysis is useful as a means to understanding the general functioning of various sectors in a specific period of time and location, but does not necessarily provide accurate assessment of the economic impacts of a drought event.

CGE models have also been used to evaluate drought impacts. They are a class of economic models which attempt to provide a view of the entire economy, using actual economic data to estimate how an economy might react to changes in policy, technology or other external factors. Gómez et al. (2004) used it in the Balearic Islands (Spain) to evaluate water use efficiency gains through water trading between agricultural and urban water uses. They also assess the economic impacts of various water allocation criteria in the Balearic Islands using the National Agricultural Accounting Network and the IO tables for 1997 to create future scenarios. The hypothetical problem of inaccuracy in the impact estimation becomes less significant here, because the alternatives are used for comparison between scenarios. Berrittella et al. (2007) simulate a Global Trade Analysis (GTA) using CGE for restricted water supply, also with data from 1997. It may be useful as an assessment for management solutions or options. The potential for informing actual management criteria for scarce resources diminishes as the lapse between the reference year used for model calibration and the projection period expands. It is also worth noting that CGE models

\footnotetext{
${ }^{1}$ Administratively Spain is divided into 17 Autonomous Communities many of which, in turn, comprise several provinces. The Ebro River basin encompasses the territory of eight Autonomous Communities.
}

serve as an analytical tool for the description of the economy of a region, but most of the parameters, such as elasticities and the coefficients of production functions, soon become outdated.

The IO and CGE methodologies are similar and both try to capture the relationships and causation chains that result in the indirect impacts of drought. Conceptually, the relevance of the indirect impacts is related to that of the direct impacts, but the multiplier effects will likely change with technology and other external factors. Therefore, impacts of drought on the agri-food industry depend on the magnitude of direct impacts on agriculture, and it is assumed that impacts tend to be attenuated as they move away from the primary sector, unless the industry itself suffers water shortages. This hypothesis is one of the main considerations of this study. Chóliz et al. (2009) also point to the close relation between agricultural water use and the use of inputs from agriculture by the agrifood industry, but in order to be relevant for our purposes the relation must be directly attributable to drought. Berrittella et al. (2007) describe water as mobile between agricultural sectors. This virtual mobility can be measured through the transmission of economic impacts or, as will be shown in this paper, through chained water-related elasticities.

The model proposed here has the advantage of being simpler than both IO and CGE as it focuses on a single sector. It can also be easily updated through the use of publicly available data bases and it aims to improve the accuracy in the attribution of supply shocks to the economic results. Nevertheless, it represents a complementary analysis to those made through IO and CGE models.

Labor utilization is also considered as an indicator of the indirect impacts of drought. Both self-employment and hired employment are presumed to be related to water availability and, therefore will be impacted by water scarcity. However, Garrido et al. (2010) and Schuh (1962) measured variations in hired labor through econometric models, and both found no significant relationship between water availability and agricultural employment. These findings are inconsistent with evaluations of drought impacts through IO and CGE models (e.g. Pérez y Pérez and Barreiro, 2009). The fact that agricultural employment is apparently not severely impacted by droughts indicates that other important variables affecting changes in employment, including time trends and technical innovation, may blur the effect of water scarcity in the agricultural labour markets.

This study addresses two sets of questions. Concerning the direct impacts of drought, the study evaluates the magnitude of the effects of drought on the value of agricultural production, trying to discriminate the effects of the lack of water from other variables that may be influencing the final output. The study also evaluates the effect of direct impacts on agroindustrial production, as an example of indirect impacts.

The main contribution of this paper to the existing literature is to create a common methodology based on econometric models that explain the relations between direct and 
indirect losses due to drought in the agri-food sector and to calculate chained elasticities in order to analyse how impacts are spread between sectors and along the value chain. Models include a number of explanatory variables obtained from general statistics, so the methodology may be replicable in other geographical locations, especially within Spain where drought and water management follows common rules.

This paper is organized into eight sections. After this introduction and review of relevant studies, we present the case study focus, the methodology and data sources. Results are presented and discussed, followed by some concluding remarks.

\section{Context and focus of the study}

The methodology proposed here follows the general econometric models developed by Garrido et al. (2010), Gil-Sevilla et al. (2010) and Gil et al. (2011) to measure drought impacts using impact attribution models. This work focuses geographically on the Ebro River basin (in northeastern Spain) and considers $15 \mathrm{yr}$ of data (1995-2009). Figure 1 represents the Ebro River basin within the country. The analysis is performed at different geographical levels, but the unit of analysis is the river basin. Data collected at different geographical scales has been processed and adapted to match the study's objectives.

The river basin dimension is appropriate for the analysis of drought impacts, because of two main reasons: (i) it is the planning and management scale established by the Water Framework Directive (Directive 2000/60/EC) (Estrela and Vargas, 2012); and (ii) from an impact assessment perspective, it is the basic unit of interrelations between direct and indirect impacts (Pérez y Pérez and Barreiro-Hurlé, 2009; Chóliz et al., 2009).

The Ebro River basin, with a total storage capacity of $7500 \mathrm{Mm}^{3}$ (MAGRAMA, 2012) and an average annual precipitation of $478 \mathrm{~mm} \mathrm{yr}^{-1}$ (AEMET, 2009), experiences recurring drought periods approximately every ten years. Iglesias et al. (2007) proposed guidelines for adequate drought management plans in Mediterranean countries. They emphasize the need for a robust system of indicators that can provide information for early detection of drought episodes and promote preparedness activities. Drought indicators in Spain were designed and evaluated starting in 2005 in an attempt to anticipate risk (Estrela and Vargas, 2012), and Drought Management Plans were approved in 2007. Drought indices consider both the availability and the demand of water to set up the thresholds that will trigger different preventive or management actions. From the point of view of water availability, indices are often simplified and refer to the predominant source of water used in each management area. In the Ebro, indices use reservoir levels as indicators in hydrologically regulated areas, streamflows in areas where there are no

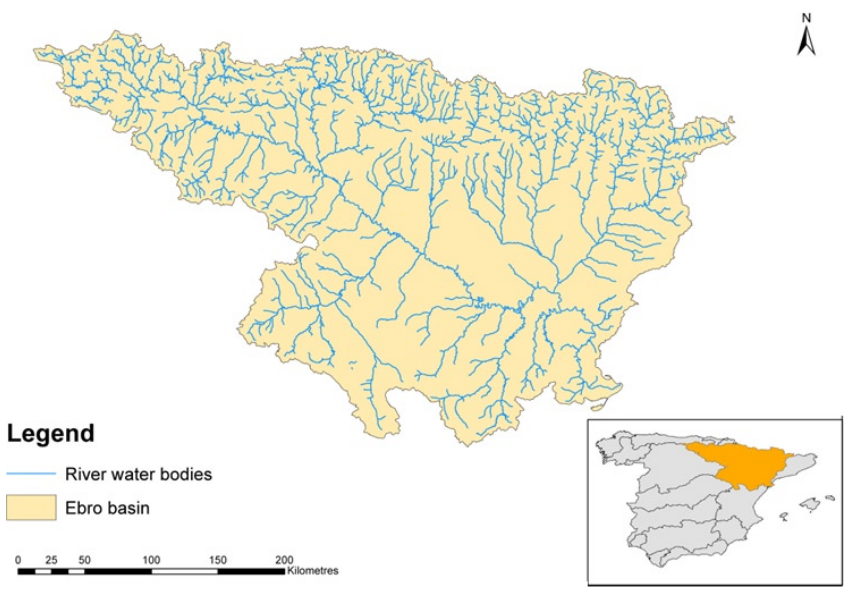

Fig. 1. Case study: the Ebro River basin and its management areas source: (CHE, 2011) (available at: http://www.chebro.es/ contenido.visualizar.do?idContenido $=12011$ \&idMenu=2224 last access: 27 January 2012). Source: Authors' elaboration.

reservoirs, or groundwater levels when these are a significant resource (rarely in the Ebro Basin).

During the period of analysis (1995-2009), the Ebro River basin experienced two major drought events: one from 1995 to 1996, and another from spring of 2005 to spring of 2008. Both events affected most river basins in Spain. Table 1 illustrates the evolution the onset of drought in the Ebro Basin through the evolution of drought indices in the main agricultural provinces of the basin affected by the drought.

\section{Methodology}

Econometric models are used to evaluate the socio-economic impacts of drought. We first fit direct attribution models and then, using the fitted variables as explanatory variables, we fit another set of attribution models to evaluate indirect impacts in the agri-food sector and in agricultural employment. The direct damages of drought are measured for both irrigated and rainfed agricultural production using economic productivity measurements as dependant variables. The indirect damages are measured in terms of agricultural employment and Gross Value Added (GVA) index of the agri-food industrial sector. For the indirect impacts an inference procedure using chained elasticities is also formulated.

\subsection{Direct attribution model}

The direct attribution model has been adapted from previous models (Garrido et al., 2010; Gil-Sevilla et al., 2010; Gil et al., 2011). In the methodology proposed in this paper, the value of production is the variable to be explained when direct damages are considered. This variable captures the variations in the value of agricultural production between 1995 and 2009. A water availability indicator is required as 
Table 1. Monthly drought indices for the main agricultural provinces in the Ebro River basin during two drought periods (1995 and $2005-$ 2008).

\begin{tabular}{|c|c|c|c|c|c|c|c|}
\hline Year & Province & November & January & March & May & July & September \\
\hline \multirow{7}{*}{1995} & Alava & 0.11 & 0.48 & 0.67 & 0.33 & 0.02 & 0.12 \\
\hline & Huesca & 0.66 & 0.63 & 0.68 & 0.36 & 0.17 & 0.11 \\
\hline & Lleida & 0.87 & 0.64 & 0.29 & 0.01 & 0.17 & 0.26 \\
\hline & La Rioja & 0.40 & 0.59 & 0.68 & 0.33 & 0.15 & 0.43 \\
\hline & Navarre & 0.56 & 0.74 & 0.76 & 0.64 & 0.46 & 0.13 \\
\hline & Teruel & 0.07 & 0.07 & 0.06 & 0.01 & 0.04 & 0.07 \\
\hline & Zaragoza & 0.76 & 0.82 & 0.88 & 0.43 & 0.14 & 0.03 \\
\hline \multirow{7}{*}{2005} & Alava & 0.51 & 0.57 & 0.77 & 0.56 & 0.36 & 0.10 \\
\hline & Huesca & 0.34 & 0.15 & 0.01 & 0.01 & 0.01 & 0.01 \\
\hline & Lleida & 0.01 & 0.02 & 0.06 & 0.15 & 0.17 & 0.01 \\
\hline & La Rioja & 0.54 & 0.39 & 0.53 & 0.58 & 0.34 & 0.43 \\
\hline & Navarre & 0.41 & 0.46 & 0.88 & 0.59 & 0.54 & 0.46 \\
\hline & Teruel & 0.42 & 0.40 & 0.29 & 0.14 & 0.04 & 0.09 \\
\hline & Zaragoza & 0.29 & 0.29 & 0.17 & 0.33 & 0.14 & 0.13 \\
\hline \multirow{7}{*}{2006} & Alava & 0.47 & 0.59 & 0.52 & 0.34 & 0.01 & 0.04 \\
\hline & Huesca & 0.19 & 0.10 & 0.36 & 0.31 & 0.22 & 0.44 \\
\hline & Lleida & 0.21 & 0.15 & 0.28 & 0.16 & 0.01 & 0.10 \\
\hline & La Rioja & 0.48 & 0.42 & 0.66 & 0.48 & 0.45 & 0.62 \\
\hline & Navarre & 0.48 & 0.77 & 0.77 & 0.49 & 0.37 & 0.36 \\
\hline & Teruel & 0.18 & 0.16 & 0.19 & 0.18 & 0.09 & 0.12 \\
\hline & Zaragoza & 0.21 & 0.32 & 0.67 & 0.52 & 0.40 & 0.73 \\
\hline \multirow{7}{*}{2007} & Alava & 0.73 & 0.01 & 0.66 & 0.63 & 0.52 & 0.25 \\
\hline & Huesca & 1.00 & 0.85 & 0.82 & 0.95 & 0.49 & 0.35 \\
\hline & Lleida & 0.18 & 0.07 & 0.01 & 0.16 & 0.11 & 0.04 \\
\hline & La Rioja & 0.64 & 0.37 & 0.41 & 1.00 & 0.68 & 0.61 \\
\hline & Navarre & 0.39 & 0.22 & 0.92 & 0.69 & 0.84 & 0.51 \\
\hline & Teruel & 0.13 & 0.03 & 0.40 & 0.49 & 0.21 & 0.12 \\
\hline & Zaragoza & 0.96 & 0.82 & 0.86 & 0.74 & 0.53 & 0.39 \\
\hline \multirow{7}{*}{2008} & Alava & 0.17 & 0.09 & 0.33 & 0.57 & 0.66 & 0.21 \\
\hline & Huesca & 0.11 & 0.01 & 0.01 & 0.93 & 0.80 & 0.58 \\
\hline & Lleida & 0.01 & 0.01 & 0.02 & 0.55 & 0.65 & 0.32 \\
\hline & La Rioja & 0.48 & 0.26 & 0.15 & 0.71 & 0.77 & 0.68 \\
\hline & Navarre & 0.32 & 0.20 & 0.40 & 0.82 & 0.72 & 0.57 \\
\hline & Teruel & 0.15 & 0.07 & 0.18 & 0.23 & 0.37 & 0.20 \\
\hline & Zaragoza & 0.22 & 0.26 & 0.29 & 0.62 & 0.70 & 0.57 \\
\hline
\end{tabular}

Source: Authors' elaboration with data from CHE. Note: values $<0.20$ indicates emergency; values $<0.30$ indicates alert and values $<0.50$ indicates pre-alert.

explanatory variable to measure the impact of drought on crops' growth and harvests. For this purpose, we selected the drought indices defined by the Ebro River basin $\mathrm{Au}$ thority (RBA) for each management area in the basin (CHE, 1995-2009) and the accumulated precipitation from January to June of each year (AEMET, 1995-2009). This period was selected because precipitation patterns during these months affect crop growth (Quiroga Gomez et al., 2010). Drought indices are used for the irrigated agriculture model and accumulated precipitation for rainfed agriculture. Each model is fitted separately. Drought indices are calculated monthly for the scale of each management area, that is generally smaller than the scale of the province used for this study. A simple linear regression between drought indices and provincial production values allows us to determine which indicator better explains the drought situation in each province. Drought indices and accumulated precipitations provide the most objective and transparent indicators of farmers' water availability. There are other causal variables that influence the economic results of both irrigated and rainfed agriculture, but they are not related to drought.

A general econometric model is proposed for both irrigated and rainfed agriculture to explain the variation in the monetary value of harvests. The variable to be explained is a 
function of a time trend, water availability, agricultural subsidies and a crop price index, as formulated in the following equation for each province $(i)$ of the Ebro River basin.

$\mathrm{Pv}_{i t}=a_{i}+b_{i} T_{t}+c_{i} \mathrm{Wa}_{i t}+d_{i} \mathrm{CAP}_{j t}+e_{i} P_{i t}+u_{i t}$,

with $u_{i}=\varepsilon_{i t}+\rho_{i} \varepsilon_{i t-1}, E\left(\varepsilon_{i t}\right)=0$ and $\sigma_{\varepsilon i}^{2}=\sigma_{i}^{2}$ where $T_{t}$ is the time variable expressed in years (from 1995 to 2009); $\mathrm{Wa}_{i t}$ is the hydrological variable water availability expressed as a drought index value for the irrigation model, and in $\mathrm{mm}$ of accumulated precipitation during the growing season for the rainfed model; $\mathrm{CAP}_{j t}$ are the Common Agricultural Policy subsidies in million $€$ at an autonomous community level $j$; and $P_{i t}$ is a crop price index for each province and each model (one for irrigation, another for rainfed).

The dependent variable $\mathrm{Pv}_{i t}$ is the production value of rainfed and irrigated agriculture, calculated using data on surface area, yields and prices for both types of agriculture, to obtain an annual provincial value in thousand of nominal $€$. An alternative option would be to evaluate the variable $\mathrm{Pv}_{i t}$ in real $€$ (current or constant) by dividing it by a price index such as $P_{i t}$. However, a nominal evaluation (in current $€)$ of $\mathrm{Pv}_{i t}$ has two advantages. First, both farmers and water managers understand economic evaluations better in nominal terms. Second, the effect of price variation is isolated from the effects of time and of water availability.

The model (Eq. 1) is fitted using the Prais-Winsten method for time series data. The Durbin-Watson statistic was calculated and the effect of serial correlation errors was corrected. Multicollinearity between $\mathrm{Wa}_{i t}, P_{i t}$ and $T_{t}$ was tested measuring the variance inflation factor (VIF) which is around 1.43 for irrigation regressions, and 1.51 for rainfed.

First, the fitted model is used to measure the impact attributable to the shortage of water for both irrigated and rainfed agriculture. The fitted model allows the comparison of an economic "normal" or "average" result with a drought-year "bad" result. This requires defining what a "normal" situation is for each type of agriculture. This is calculated with the fitted model by introducing an average value of the water availability variable $\left(\mathrm{Wa}_{i}\right)$ to obtain the $\mathrm{Pv}_{i t}$ that would result in a year of normal water availability and without altering the other conditions of year $t$ and province $i$.

For irrigated agriculture the "normal" water availability variable is the drought index of normal conditions when the drought index falls between 0.5 and 1 , water supply is considered sufficient to satisfy all demands, while drought indices below 0.5 indicate pre-alert, alert or emergency situations according to the thresholds established by the Ebro Special Drought Management Plan. Therefore, 0.5 has been selected as the value above which the water availability variable is considered "normal". The drought index has not risen above 0.75 since it started being calculated (CHE, 2011), and no drought management measures are implemented until the index falls below 0.3 (alert status).

In the case of rainfed agriculture the "normal" water availability is calculated with the moving average of rainfall from the previous $3 \mathrm{yr}$ (Eq. 2), where $R_{i t}$ is the accumulated rainfall for each province and each year.

$\bar{R}_{i t}=\frac{\sum_{i-3}^{i-1} R_{i t}}{3}$

Those "normal" variables are introduced into each fitted model to obtain the average production value for each year in order to compare this value with the one obtained with the model in drought years (Eq. 3).

$\overline{\mathrm{PV}}_{i t}=\hat{a}_{i}+\hat{b}_{i} T_{t}+\hat{c}_{i} \overline{\mathrm{W}} \mathrm{a}_{i t}+\hat{d}_{i} \mathrm{CAP}_{i t}+\hat{e}_{i} P_{i t}+u_{i t}$,

where $\overline{\mathrm{PV}}_{i t}$ is the "normal" production value, $\overline{\mathrm{W}} \mathrm{a}_{i t}$ is the normal water availability, that is, the "normal" drought index for the irrigated agriculture model, or the accumulated average rainfall for the rainfed agriculture one. The normal production value $\left(\overline{\mathrm{Pv}}_{i t}\right)$ provides the values that would have been obtained in each province if a sufficient amount of water had been available. It can also be expressed in a range of values if we consider the error term $\left(u_{i}\right)$ of the model. The result $\left(\overline{\mathrm{Pv}}_{i t}\right)$ can be compared with the result obtained with less water (lower drought index or less precipitation) $\left(\hat{\mathrm{Pv}}_{i t}\right)$ for each year (fitted Eq. 1). The comparison of both values leads us to the economic impact due to lower drought index or lower precipitation, which means lower water availability in each case. Therefore, direct impacts $\left(\mathrm{Di}_{i t}\right)$ for a specific year $t$ are the following for each province $i$ :

$\mathrm{Di}_{i t}=\hat{\mathrm{Pv}}_{i t}-\overline{\mathrm{Pv}}_{i t}$

\subsection{Indirect attribution model: two step model}

The second component of the methodological approach is also based on econometric models. The objective of the methodology is to clearly identify which variables are directly related to the lack of water and to identify how these variables indirectly affect agro-industrial production and agricultural employment.

To evaluate the economic variations of indirectly affected variables, an indirect attribution model (two-step model) is proposed. The aim of this part of the methodology is to explain the evolution of agri-food industrial gross value added (GVA) and agricultural employment through models fitted in two steps. The first step measures the direct relations and the second step measures the indirect relations. The explanatory variables are the fitted variables obtained from the models developed to estimate irrigated agriculture and rainfed agriculture production values (Eq. 1).

Indirectly affected variables (indirect variables hereafter) are modelled in an attempt to obtain better estimations of drought losses. The model proposed in step two estimates indirect variables depending on fitted Irrigated production value and fitted rainfed production value (from step one, Eq. 1) as Eq. (5) indicates:

$\mathrm{Iv}_{i t}=a_{i}+b_{i} \mathrm{I} \hat{\mathrm{p}} \mathrm{v}_{i t}+c_{i} \mathrm{R} \hat{\mathrm{p}} \mathrm{v}_{i t}+\varepsilon_{i t}$, 
with $E\left(\varepsilon_{\mathrm{i}}\right)=0$ and $\sigma_{i t}^{2}=\sigma^{2}$, where $\mathrm{Iv}_{i t}$ (indirect variable) refers commonly to agri-food industrial GVA or agricultural employment, but both are estimated separately. $I \hat{p} v_{i t}$ is the fitted Irrigation production value, and $I \hat{p} v_{i t}$ the fitted rainfed production value. These two are estimated from the models formulated by Eq. (1).

Although the trend has been omitted as an explanatory variable, it is included as the time trend for both fitted irrigation production value (Ipv) and rainfed production value (Rpv). Different alternatives have been tested to eliminate the trend and isolate the variances on indirect variables from strong trends over time. But, as will be shown in the results section, one of the most significant factors influencing indirect variables is the trend in agricultural production, thus it cannot be omitted. Multicollinearity between explanatory variables has also been tested with the VIF statistic, and results show that there are not multicollinearity problems, with values ranging between 1.71 (for agri-food industrial GVA) and 1.78 (for employment).

Additionally, linear simple regressions between $\mathrm{Iv}_{i t}$ and actual or fitted irrigation production value and, separately, regressions between $\mathrm{Iv}_{i t}$ and actual or fitted rainfed production value have been done. Results show that there is a relation between directly affected variables and indirect sectors (Fig. 3 shows the regression lines referred to the regions).

\subsection{Spread of impacts: chained elasticities}

An additional approach based on inference procedures is proposed to measure the spread of drought impacts from agricultural production to the main indirect variables affected. By calculating different elasticities the spread of impacts from directly affected variables to indirectly affected ones can be estimated. We consider a neoclassical model in the tradition of Solow (1956), where elasticities can be extracted from an adaptation of the econometric models formulated in previous sections. Equations (1) and (5) are transformed into logarithmic form and reflected in the following production functions:

$$
\begin{aligned}
& \mathrm{Rpv}=e^{\theta_{i}+\lambda_{i} T} \mathrm{Wa}_{2}{ }^{\mu_{i}} \mathrm{CAP}^{\rho_{i}} P^{\xi_{i}} \\
& \mathrm{Ipv}=e^{\delta_{i}+\varepsilon_{i} T} \mathrm{Wa}_{1}{ }^{\zeta_{i}} \mathrm{CAP}^{\varphi_{i}} P^{\eta_{i}} \\
& \mathrm{Iv}=e^{\alpha_{i}} \mathrm{I} \hat{\mathrm{p}} \mathrm{v}^{\beta_{i}} \mathrm{R} \hat{\mathrm{p}} \mathrm{v}^{\gamma_{i}}
\end{aligned}
$$

The elasticities found in this equation system (Eqs. 6, 7 and 8) are divided into two groups: some dependant on water availability (water for irrigation or precipitation in the case of rainfed agriculture) and others dependant on irrigation or rainfed productions. The elasticities are the following:

$\beta_{i}=\frac{\partial \log \mathrm{Iv}}{\partial \log \mathrm{Ipv}} ; \quad \gamma_{i}=\frac{\partial \log \mathrm{Iv}}{\partial \log \mathrm{Rpv}}$
and $\zeta_{i}=\frac{\partial \log \mathrm{Ipv}}{\partial \log \mathrm{Wa}_{1}} ; \quad \mu_{i}=\frac{\partial \log \mathrm{Rpv}}{\partial \log \mathrm{Wa}_{2}}$

None of them measure the elasticity between water availability and indirect variables. However, variations on either irrigation water availability $\left(\mathrm{Wa}_{1}\right)$ and/or rainfed water availability $\left(\mathrm{Wa}_{2}\right)$ may have an impact on indirect variables. Since there is a relation between indirectly and directly affected variables, and moreover directly affected variables are related to water availability, a combination of elasticities would lead us to obtain how the impacts are transmitted. By substituting Eqs. (6) and (7) into Eq. (8), the following equations are obtained:

$$
\begin{aligned}
\operatorname{Iv}_{i t}= & e_{i}^{\alpha}\left(e^{\delta_{i}+\varepsilon_{i} T} \mathrm{Wa}_{1}{ }^{\zeta_{i}} \mathrm{CAP}^{\varphi_{i}} P^{\eta_{i}}\right)^{\beta_{i}} \\
& \left(e^{\theta_{i}+\lambda_{i} T} \mathrm{Wa}_{2}{ }^{\mu_{i}} \mathrm{CAP}^{\rho_{i}} P^{\xi_{i}}\right)^{\gamma_{i}} \\
\mathrm{Iv}_{i t}= & e^{\alpha_{i}}\left(\left(e^{\delta_{i}+\varepsilon_{i} T}\right)^{\beta_{i}}\left(\mathrm{Wa}_{1}{ }^{\zeta_{i} \beta_{i}}\right)\left(\mathrm{CAP}^{\varphi_{i} \beta_{i}}\right)\left(P^{\eta_{i} \beta_{i}}\right)\right) \\
& \times\left(\left(e^{\theta_{i}+\lambda_{i} T}\right)^{\gamma_{i}}\left(\mathrm{Wa}_{2}{ }^{\mu_{i} \gamma_{i}}\right)\left(\mathrm{CAP}^{\rho_{i} \gamma_{i}}\right)\left(P^{\xi_{i} \gamma_{i}}\right)\right)
\end{aligned}
$$

No contemporaneous relation is assumed between accumulated precipitation for rainfed crops ( $\mathrm{Wa}_{2}$, spanning only 5 months) and drought indices that use reservoir storage values as primary indicators $\left(\mathrm{Wa}_{1}\right)^{2}$. The partial derivative of indirect variable by $\mathrm{Wa}_{1}$ would be $\zeta_{i} \beta_{i}$ (Elasticity of Indirect variables in relation to irrigation water) and the partial derivative of indirect variable by $\mathrm{Wa}_{2}$ is $\mu_{i} \gamma_{\mathrm{i}}$ (Elasticity of Indirect variables in relation to rainfed water) form Eq. (10).

\section{Data sources}

The main variables measured in this study, and used as independent variables on the econometric models, are: (i) economic production value (distinguishing irrigated agriculture and rainfed agriculture); (ii) GVA of the agri-food industry; and (iii) agricultural employment (both self-employed and hired labour, collected from Spanish Social Security data for the period 1999-2009).

Each production value $\left(\operatorname{Ipv}_{i t}\right.$ and $\left.\mathrm{Rpv}_{i t}\right)$ is calculated as follows:

$\mathrm{Pv}_{i t}=\sum_{j=1}^{94} S_{j i} \times Y_{j i} \times p_{j t}$

where $S_{j t}$ is the irrigated or rainfed surface area in province $i$, year $t$, and crop $j(j=1, \ldots, 94), Y_{j t}$ denotes the yield of each crop (differentiating irrigated or rainfed) in province $i$ and year $t$, and $p_{j t}$ is the national on-farm price for each crop in year $t$.

Agricultural GVA is collected from the Spanish National Statistics Institute for a time series that spans between 1995 and 2010 at the regional level (autonomous community) and is measured in nominal Euro. Employment is also collected

\footnotetext{
${ }^{2} R^{2}$ resulting from an OLS regression between drought indices and accumulated precipitation is 0.04 and the $p$ value is not significant $(0.133)$. Both variables are certainly related in a longer term period (interannual).
} 
Table 2. Regression results from Direct Attribution models. Correlation coefficients and significance of explanatory variables.

\begin{tabular}{|c|c|c|c|c|c|c|c|c|c|c|}
\hline \multirow{2}{*}{ Provinces } & \multicolumn{5}{|c|}{ Irrigated production value } & \multicolumn{5}{|c|}{ Rainfed production value } \\
\hline & $R^{2}$ & $T$ & $\mathrm{Wa}_{1}$ & $P$ & CAP & $R^{2}$ & $T$ & $\mathrm{Wa}_{2}$ & $P$ & CAP \\
\hline Alava & 0.29 & -742.99 & $21991.21 *$ & 223.11 & 343.03 & 0.87 & 1125.45 & 44.41 & $-198.85 * * *$ & -514.45 \\
\hline Huesca & 0.83 & $23361.95^{* * *}$ & $103043.80 * *$ & $-3669.75 * *$ & $-460.19 * *$ & 0.75 & $6160.17 * *$ & $240.55 * * *$ & -442.1395 & $-311.89 * *$ \\
\hline Lleida & 0.91 & 5686.71 & 79064.39 & 1790.06 & 72.90 & 0.86 & $-5264.45^{* * *}$ & $173.44 * *$ & 647.1151 & 84.49 \\
\hline La Rioja & 0.66 & 1989.99 & -5154.58 & 324.14 & $1764.85 * *$ & 0.23 & 1452.42 & 15.64 & -188.04 & -559.39 \\
\hline Navarre & 0.99 & $13169.22 * * *$ & 13666.95 & $1301.606^{* *}$ & $-420.46^{*}$ & 0.76 & 2556.83 & 128.00 & -1101.17 & -105.71 \\
\hline Teruel & 0.71 & -244.64 & -10236.96 & 1513.63 & $-47.11 * *$ & 0.79 & 1561.14 & $204.5 * * *$ & 540.67 & -134.89 \\
\hline Zaragoza & 0.98 & $35357.07 * * *$ & $100171.40 * *$ & $-8215.89 * * *$ & -220.60 & 0.65 & 5690.32 & 294.34 & 766.75 & -225.91 \\
\hline
\end{tabular}

*** $p<0.01 ; * * p<0.05 ; * p<0.1,(n=14$ observations $)$.

from official data from the Social Security Administration from 1999 until 2009 in the number of self-employed and hired workers per province.

Additionally, a weighted price index has been built for each geographical unit and each type of agriculture (denoted by $P_{i t}$ ) to capture the variations in product value due to crop price variations. This index takes into account the importance of each group of crops (twelve groups: cereals, fruits, industrial crops, etc.) within each unit and is calculated using the following formula:

$P_{i t}=\frac{\sum_{k=1}^{12} \mathrm{Pvt}_{i k t} \times P_{k t}}{\mathrm{Pv}_{i t}}$,

where $\mathrm{Pvt}_{i k t}$ is the total value of crop group $k(k=1, \ldots, 12)$, which is representative of the crops grown in each province. All 94 crops were included in these 12 groups so that each group has a specific price index, $P_{k t}$, which is published by the official statistical source (MAGRAMA, 1995-2009).

Common Agricultural Policy (CAP) subsidies have been obtained from the FEGA ("Spanish Agricultural Guarantee Fund") database for the 1997-2009 period. Data for 1995 and 1996 has been assumed to be the same as in $1997^{3}$.

Elasticity values obtained from $\zeta_{i} \beta_{i}$ and $\mu_{i} \gamma_{i}$ are used to measure the impacts on agri-industrial GVA attributable to water availability, as indicated in Eq. (12). To calculate GVA impact at an autonomous community level from provinciallevel elasticities of water availability, percentages of production importance of provinces in the corresponding autonomous community must be calculated and applied.

$\Delta \mathrm{GVA}(\%)=\zeta_{i} \beta_{i} \times \Delta \mathrm{Wa}_{1}(\%)$

$\Delta \mathrm{GVA}(\%)=\mu_{i} \gamma_{i} \times \Delta \mathrm{Wa}_{2}(\%)$

The impact of a drought year is calculated in reference to the average water availability for each case, which is the normal drought index (0.5) or the average rainfall for previous years (Eq. 2).

\footnotetext{
${ }^{3}$ Before FEGA managed CAP subsidies, FORPA ("Fund Management of Agricultural Products") and SENPA ("National Service of Agricultural Products") had that role. Data from those organizations is not available.
}

\section{Results: drought attribution models and estimated elasticities}

Table 2 reports the results from the direct attribution econometric models (Eqs. 1 and 5). The left part corresponds to the results of the irrigated agriculture models and the right part to the rainfed agriculture models. The majority of the coefficients of determination $\left(R^{2}\right)$ are above 0.60 and almost $50 \%$ of them are above 0.70 . This means that the variations of the dependent variables are moderately well explained by the explanatory variables used. Although different results can be seen for the $R^{2}$ depending on the province considered, fitted results for the provinces of Alava for irrigated agriculture or La Rioja for rainfed agriculture, for instance, are very poor. By contrast, those provinces where the model offers high values of $R^{2}$ allow for a more accurate estimation of drought impacts.

The water availability variables used in the rainfed model are better able to explain the evolution of agricultural production values. Rainfall variation is a very good explanatory variable for the value of rainfed agricultural production (most of them are significant or very significant, $p<0.05$ ). However, irrigated production models (left panel) offer a less accurate explanation of the evolution of irrigated agricultural production values as a result of variations in water availability expressed through drought indices, with prices being more important and the trend $(T)$ being the most significant explanatory variable. The value of rainfed agricultural production is less affected by price variations than that of irrigated agriculture, where outputs have higher price levels and higher market risks. Despite this, the coefficients of price indexes are negative in a few provinces, which may capture the cases when agricultural production output is low, supply decreases and, therefore prices increase. CAP subsidies are relevant in some provinces, but with ambiguous results.

Table 3 reports the results from the econometric models of indirect variables, in the left side results for the GVA of the agri-food industry (at the level of autonomous community) are presented, and on the right side the results from the employment models (divided into two types: family and hired labour) are shown. Overall results suggest that the proposed 
Table 3. Regression results of two step models for indirect impacts of drought: agri-food industrial GVA (regional level) and employment (provincial level). Correlation coefficients and significance of explanatory variables.

\begin{tabular}{|c|c|c|c|c|c|c|c|c|c|c|}
\hline \multirow[b]{3}{*}{$\begin{array}{l}\text { Autonomous } \\
\text { communities }\end{array}$} & \multicolumn{7}{|c|}{ Indirect impacts } & & & \\
\hline & \multicolumn{3}{|c|}{ GVA agri-food industry } & \multirow[b]{2}{*}{ Provinces } & \multicolumn{3}{|c|}{ Family labor } & \multicolumn{3}{|c|}{ Hired labor } \\
\hline & $R^{2}$ & $\mathrm{R} \hat{\mathrm{p}} \mathrm{v}$ & $\mathrm{I} \hat{\mathrm{p} v}$ & & $R^{2}$ & $\mathrm{R} \hat{\mathrm{p} v} \mathrm{v}$ & Ip $\mathrm{p} v$ & $R^{2}$ & $\mathrm{R} \hat{\mathrm{p}} \mathrm{v}$ & $\mathrm{I} \hat{\mathrm{p}} \mathrm{v}$ \\
\hline B. Country 1 & 0.52 & 26.85 & $90.94 * * *$ & Alava & 0.75 & -0.01 & $-0.03 * * *$ & 0.60 & $0.02 * *$ & 0.08 \\
\hline \multirow[t]{2}{*}{ Navarre } & 0.97 & 7.77 & $9.39 * * *$ & Navarre & 0.98 & $-0.03 * *$ & $-0.02 * * *$ & 0.66 & $0.03 * *$ & -0.03 \\
\hline & & & & Zaragoza & 0.68 & 0.004 & $-0.01 * *$ & 0.15 & -0.01 & 0.001 \\
\hline \multirow[t]{2}{*}{ Aragon } & 0.71 & $-6.74^{*}$ & $5.49 * * *$ & Huesca & 0.51 & $0.07 *$ & $-0.03 *$ & 0.08 & -0.003 & 0.0001 \\
\hline & & & & Teruel & 0.35 & -0.01 & -0.13 & 0.33 & 0.00 & 0.03 \\
\hline La Rioja & 0.63 & $21.45 * *$ & $7.12 * * *$ & La Rioja & 0.91 & $-0.06^{* * *}$ & $-0.01 * * *$ & 0.67 & $0.10 *$ & $0.03 *$ \\
\hline Catalonia & 0.91 & $-86.80 * * *$ & $48.41 * * *$ & Lleida & 0.90 & $0.07 * * *$ & $-0.03 * * *$ & 0.81 & $-0.03 * *$ & 0.02 \\
\hline
\end{tabular}

(1) Basque Country; *** $p<0.01 ; * * p<0.05 ; * p<0.1$.

methodology is consistent, because moderately high values of $R^{2}$ and coefficients of statistical significance are reported.

A more detailed assessment of the results shows how irrigated agricultural production is the main explanatory variable for agri-food GVA in almost all cases. Irrigated agricultural production is the main input for agri-food industry. Furthermore, the strong trend followed by the irrigation sector was accompanied by the variation of the total GVA of the industry related to agricultural products. Regarding employment, a negative sign is predominant for both rainfed and irrigation, which may indicate that employment variation is not dependent on water and production variations. In this case, a strong negative trend is obtained making it difficult to accurately measure the impacts attributable to water scarcity.

Elasticities calculated to identify the transmission of drought impacts to agri-food industry GVA are reported in Table 4. The significance obtained from the fits is also reported. Elasticities between GVA and water availability show no significance, because they are obtained by multiplying the other estimated elasticities. Elasticity between irrigation production and water availability $\left(\zeta_{i}\right)$ ranges between 0.10 and 0.20 when it is significant, whereas rainfed elasticity $\left(\mu_{i}\right)$ varies between 0.23 and 0.57 if significant. Rainfed agricultural production is more affected by variations in water availability (precipitation) than irrigated production, that usually has a higher supply guarantee.

The left part of Table 4 reports estimated direct elasticities and the right part the indirect effects. All of them allow for the estimation of the impacts transmitted through the elasticity factors. $\zeta_{i}$ and $\mu_{i}$ represent the effect that changes in water availability have in production values. These effects are the first to appear as the result of drought, and are transmitted to the macro-economic variable through $\beta_{i}$ and $\gamma_{i}$. The left part of Table 4 measures the same transmissions directly. That is, the factors reported there measure how changes in water availability produce changes in the macro-economic variables.
The elasticities are empirically applied to either measure actual losses or potential losses in hypothetical water scarcity scenarios. This gives a perspective of the vulnerability and the risk of each geographical unit. For example in the province of Zaragoza (within the autonomous community of Aragon), where $\zeta_{i}=0.20(p<0.01)$, a decrease of $1 \%$ in water availability would be reflected in a decrease of $0.20 \%$ in irrigated production value, and this decrease $(0.20 \%)$ is transmitted to the agri-food GVA as a decrease of $0.17 \%$ in value (the indirect effect of $\zeta_{i} \beta_{i}$ ). In a scenario of drought (for the same province) where the hypothetical reduction of water reaches $50 \%$, the value of agricultural production would decrease by up to $10 \%$, and agri-food GVA would decrease by up to $8.5 \%$.

In the case of rainfed agricultural production in Huesca (also within the autonomous community of Aragon), where $\mu_{i}=0.57 \quad(p<0.01)$, the same hypothetical decrease of $50 \%$ in water availability would result in a reduction of $28.5 \%$ in the value of rainfed agricultural production (double the impact than the one recorded for irrigated productions in Zaragoza), and a decrease of only $4 \%$ in agri-food GVA values (measured through $\gamma_{i} \mu_{i}$ ).

\section{The economic impacts of drought in the agricultural sector}

This section presents the economic impacts suffered in the two drought periods considered in this study (the one occurred in 1995 and the other between 2005 and 2008).

Direct impacts are measured comparing a "normal situation" (that is, the result of the model with normal water availability) and what the model predicts for a dry year (Eq. 4). Figure 2 shows the comparison between a normal situation, the models' predicted values, and the actual values of both irrigated and rainfed production values in the provinces of Huesca, Lleida (in Catalonia), Zaragoza and Teruel, that 
Table 4. Economic variables elasticity in relation to water availability.

\begin{tabular}{|c|c|c|c|c|c|c|c|c|c|c|c|c|c|c|c|}
\hline \multirow{3}{*}{$\begin{array}{l}\text { Province } \\
\text { Alava }\end{array}$} & \multirow{3}{*}{$\begin{array}{l}\begin{array}{l}\text { Autonomous } \\
\text { community }\end{array} \\
\text { B. Country }\end{array}$} & \multicolumn{12}{|c|}{ Direct elasticities } & \multicolumn{2}{|c|}{ Indirect Effects } \\
\hline & & \multirow{2}{*}{$\begin{array}{c}\beta_{i}^{1} \\
9 * *\end{array}$} & \multicolumn{2}{|c|}{ Conf Interv } & \multirow{2}{*}{$\begin{array}{r}\gamma_{i}^{2} \\
-0.24^{* *}\end{array}$} & \multicolumn{2}{|c|}{ Conf Interv } & \multirow{2}{*}{$\begin{array}{c}\zeta_{i}^{3} \\
0.07\end{array}$} & \multicolumn{2}{|c|}{ Conf Interv } & \multirow{2}{*}{$\begin{array}{r}\mu_{i}^{4} \\
0.12\end{array}$} & \multicolumn{2}{|c|}{ Conf Interv } & \multirow{2}{*}{$\begin{array}{l}\zeta_{i} \beta_{i}^{5} \\
0.07\end{array}$} & \multirow{2}{*}{$\begin{array}{r}\gamma_{i} \mu_{i}^{6} \\
-0.03\end{array}$} \\
\hline & & & $(0.28$ & 1.81) & & $(-0.48$ & $-0.006)$ & & $(-0.26$ & $0.40)$ & & $(-0.37$ & $0.62)$ & & \\
\hline Navarre & Navarre & $1.10 * * *$ & $(0.72$ & $1.48)$ & 0.51 & $(-0.24$ & $1.26)$ & 0.02 & $(-0.04$ & $0.08)$ & 0.26 & $(-0.17$ & $0.69)$ & 0.02 & 0.13 \\
\hline Lleida & Catalonia & $1.56 * * *$ & $(0.74$ & $2.38)$ & $-0.48^{* * * *}$ & $(-0.72$ & $-0.24)$ & 0.002 & $(-0.06$ & $0.07)$ & $0.27 * *$ & $(0.002$ & $0.53)$ & 0.003 & -0.13 \\
\hline La Rioja & La Rioja & $1.08 * * *$ & $(0.45$ & $1.72)$ & $1.67^{*}$ & $(-0.02$ & $3.35)$ & -0.01 & $(-0.10$ & $0.08)$ & -0.02 & $(-0.34$ & $0.29)$ & -0.01 & -0.04 \\
\hline Huesca & & & & & & & & $0.09 *$ & $(-0.005$ & $0.19)$ & $0.52 * * *$ & $(0.23$ & $0.82)$ & 0.14 & -0.13 \\
\hline Zaragoza & Aragon & $1.48 * * *$ & $(0.91$ & $2.06)$ & $-0.26^{*}$ & $(-0.56$ & $0.04)$ & $0.25^{* * *}$ & $(0.12$ & $0.38)$ & 0.34 & $(-0.17$ & $0.84)$ & 0.36 & -0.09 \\
\hline Teruel & & & & & & & & -0.04 & $(-0.11$ & $0.02)$ & $0.49 * *$ & $(0.10$ & $0.89)$ & -0.06 & -0.13 \\
\hline
\end{tabular}

$*_{* *}^{*} p<0.01 ; * * p<0.05 ; * p<0.1$. (1) Elasticity of GVA with respect to Irrigation productions. (2) Elasticity of GVA with respect to rainfed productions. (3) Elasticity of Irrigation productions with respect to water availability for irrigation. (4) Elasticity of Rainfed productions with respect to water availability for rainfed. (5) Elasticity of GVA with respect to availability for irrigation. (6) Elasticity of GVA with respect to availability for rainfed.

were the most affected in the Ebro River basin (see Figs. 1, 2 and 3). Total production value in current $€$ is represented in red, whereas the blue line defines the value predicted by the model, and the grey line is the normal production value along with the range delimited by dashed lines that include the models confident intervals of the predicted values. Most of the fluctuations in the evolution of both real and projected production values are followed by both lines. This relation is very clear for irrigation production in Huesca and Zaragoza, for instance. Total losses will be defined in a drought year by the distance between the grey and blue lines. This means that the difference between those two modelled values is attributable to the difference in water availability and, therefore, it represents the economic impact attributable to water scarcity. Losses that exceed the range of error indicate a strong economic impact in the provinces analysed.

All provinces represented in Fig. 2 show an important decrease in production values in 1995 and 2005. Furthermore the real decrease (red line) is always greater than what the model predicts (green line), except for the case of Lleida. However, the entire decrease in agricultural output cannot be attributed to water shortages. The model used here provides a method to discriminate the percentage of the variance attributable to changes in water availability, from the sources of variation captured by the time trend or prices changes. To isolate the water scarcity effect we measure the difference between production value predicted with the model (in years where water availability is lower than normal) and the "normal" production value (with "normal" water availability included in its calculation). In all cases the real decrease of the economic value was below the decrease due to drought. If the models' goodness-of-fit is good, then we can assume that there are other sources of losses that cannot be attributable to drought. In these figures we also represent by a dashed line the standard deviation of the error term and, hence, there are a range of values among which the production value may naturally vary.

Table 5 shows the economic impacts of these drought periods on irrigated and rainfed agriculture, in the different provinces and for the whole Ebro Basin. Major losses occur in 1995 and 2005. Losses in 2005 are particularly severe and exceed 200 million $€$. The impact subsided during the following years of the drought period, but remained significant until 2008 for irrigation. The province of Huesca was particularly affected in 2005 and 2006. On the other hand, impacts on rainfed agriculture were more uniformly distributed throughout the basin. Pérez y Pérez and BarreiroHurlé (2009) estimate the total loss of agricultural production in 482 million $€$ for 2005 , while the model proposed here estimates a total loss of 209 million $€$ (calculated as the sum of impacts for both types of agriculture). With the benefit of hindsight, and considering the variations of agricultural production around the trend, our evaluation may be more accurate because it was based on actual measurements before and after the drought.

Table 5 summarizes all direct impacts calculated for both drought periods in the Ebro River basin with the linear models, that is, comparing fitted models with expected "normal" or "average" results, as explained in Sect. 4.1 of this article. The percentage of the total reduction in the value of production that is attributable to water scarcity is also indicated. This percentage is calculated with reference to the total decrease in production value, that is, the difference between the actual production value and the trend. This percentage is a comparison between actual production decreases and model predicted impacts. There are cases where the model predicts an impact due to water scarcity, but the final output was above the trend and, therefore, no percentage is shown in Table 5. There are other cases where an impact was identified and a decrease occurred and, therefore, the percentage represented in Table 5 is the amount of the loss attributable to water shortages.

Indirect impacts appear to be closely related to irrigation and rainfed production values and are thus related to the water used for those productions. The evolution of agri-food industrial GVA shows this behaviour, but employment is more disengaged from water availability (see Table 3 ). The negative signs obtained (Table 3), especially in hired labour, show how employment is following a decreasing trend instead of being affected by water variability. This is the main reason 

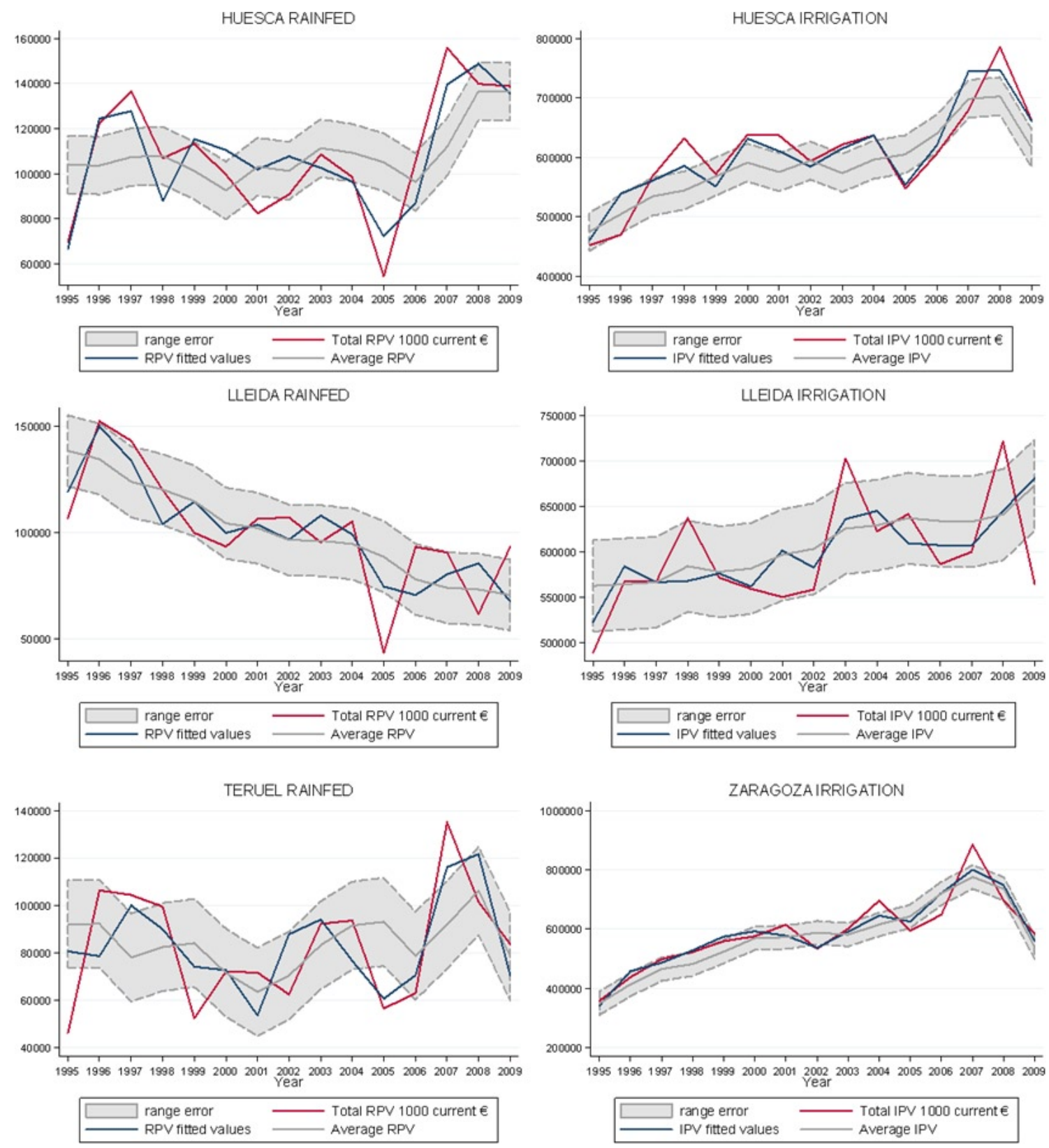

Fig. 2. Production values of rainfed and irrigated agriculture (thousand of current $€$ ) in the provinces of Huesca, Lleida and Teruel (19952009). Observed data, predicted value, average values and confident intervals. Source: authors' elaboration

for not calculating the precise impacts for labour. The same situation can be observed for rainfed productions in Lleida, the strong negative trend prevents us from relating it with droughts and thus, from calculating its impact on GVA.

Model results indicate that agri-food industrial GVA is not directly related to water scarcity, but it suffers the impacts of drought through impacts on the main direct variables affected. The irrigation production value is the most significant explanatory variable on the indirect models (see Table 3), Fig. 3 depicts the relation between the GVA and irrigated production value by a quadratic fit with the $95 \%$ confidence interval.

The proposed inference method to measure the indirect impacts provides a variety of elasticities to measure the relation between water availability and GVA, and also between agricultural productions and GVA (see Table 4). The spread of the impacts through the value chain can be described through chained elasticities. Thus the calculated elasticities produce two types of impacts on agri-industrial GVA: one due to drought impacts on rainfed productions and the other due to drought impacts on irrigation. The addition of both 

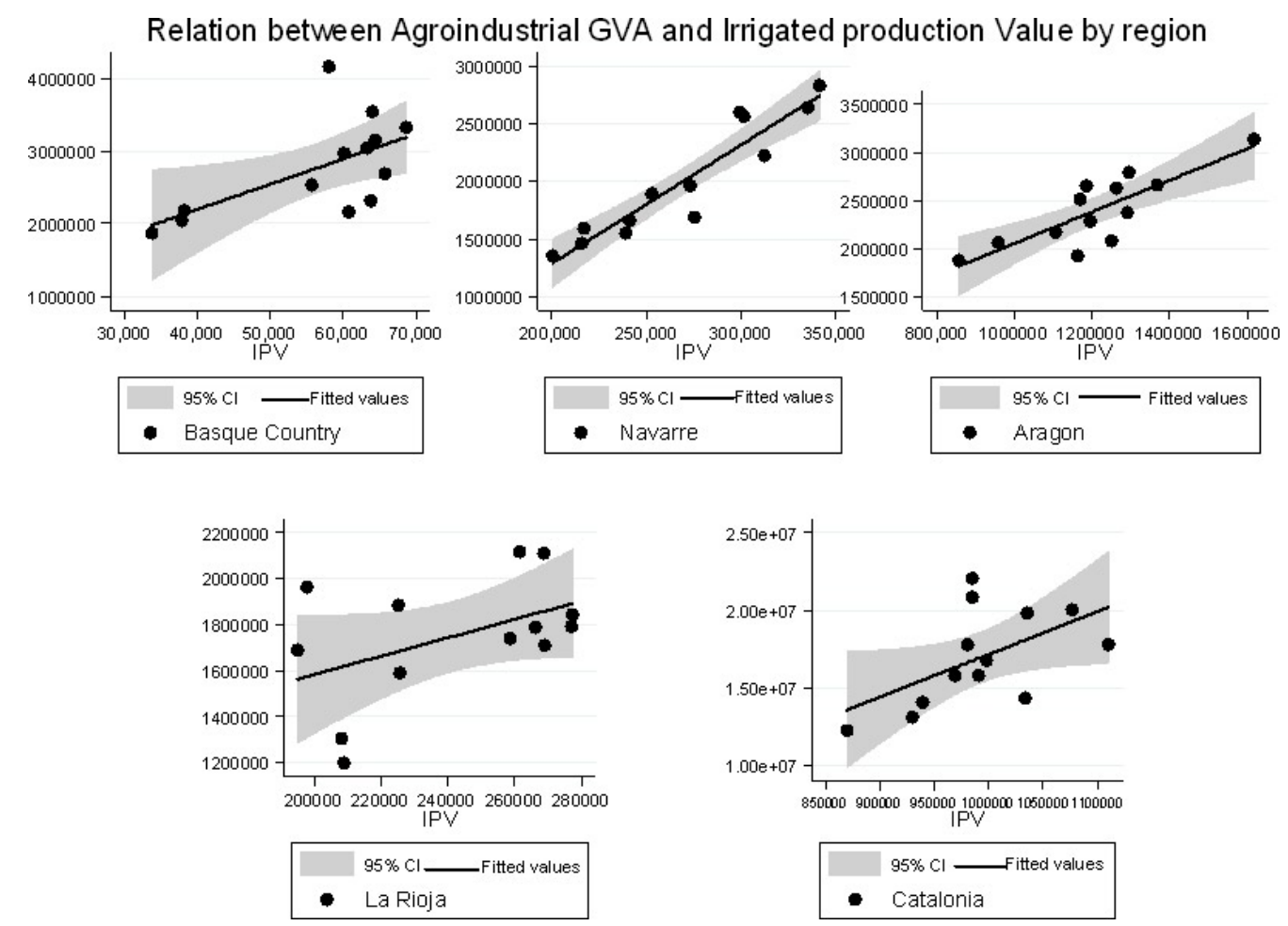

Fig. 3. Relation between observed irrigated production value (IPV, on $x$ axis) and agri-food industrial output (GVA, on $y$ axis). Source: authors' elaboration, both axis are measured in $1000 €$.

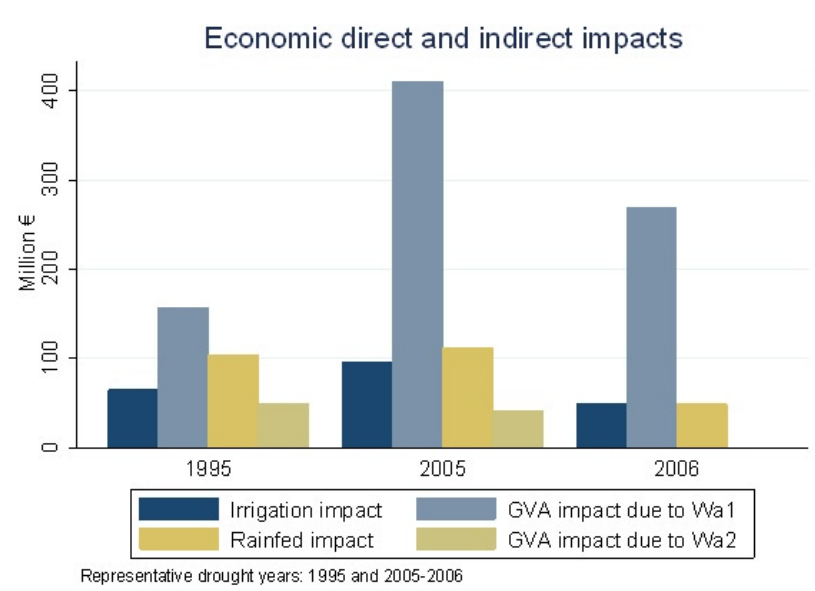

Fig. 4. Comparison of the amount of direct and indirect impacts of the 2004-2008 drought on the Ebro River basin (million $€$ ).

types of impacts is the impact produced on GVA and attributable to water scarcity.

Table 6 shows the results of those calculations (made with the logarithmic models explained on Sect. 4.3 of this article) for the driest years of the drought periods (1995, 2005 and 2006) and for irrigated and rainfed agriculture respectively. The first two columns of each part of the table show the variation of water availability with respect to the average expressed in percentage terms; the next two columns the percentages of direct and indirect impacts transmitted through elasticities are shown, as is the impact on agri-food GVA in million $€$. It is important to remark that these values are the total amount attributable to water availability without considering the actual production value decreases. Elasticities are a relative measure of the loss that must be transmitted between variables.

The case of Huesca in 2005 is a clear example of how the impacts on irrigation are transmitted to GVA. Variations of $97 \%$ in water availability produce a $9.04 \%$ impact on irrigation production. In the three provinces of the autonomous community of Aragón (Huesca, Teruel and Zaragoza), reduced irrigation production translates in a $13.39 \%$ impact on GVA, which is 367.59 million $€$. Another fact must be considered: percentages transmitted to GVA always produce greater impacts because GVA total value is greater than IPV or RPV total values, but the percentage change remains lower. GVA is a processing industry and can source itself from other suppliers.

Results from Pérez y Pérez and Barreiro-Hurlé (2009) for the indirect impacts are smaller than the results calculated using the elasticities methodology described here. They report a total impact on GVA of 202 million $€$ for the whole Ebro River basin in 2005, while the elasticities here indicate that it may be twice that amount. The propagation of 
Table 5. 2005-2008 direct impacts, percentage of the total decrease in the value of production attributable to water scarcity.

\begin{tabular}{|c|c|c|c|c|c|c|c|c|}
\hline Year & Province & $\begin{array}{l}\text { Autonomous } \\
\text { community }\end{array}$ & $\begin{array}{r}\text { Impact on } \\
\text { irrigation } \\
\text { (million } € \text { ) }\end{array}$ & $\begin{array}{r}\% \text { of irrigation } \\
\text { losses from } \\
\text { total loses }\end{array}$ & $\begin{array}{r}\text { Impact on } \\
\text { rainfed } \\
(\text { million } €)\end{array}$ & $\begin{array}{c}\% \text { of rainfed } \\
\text { losses from } \\
\text { total losses }\end{array}$ & $\begin{array}{r}\text { Total yearly } \\
\text { irrigation loss } \\
\text { (million } €)\end{array}$ & $\begin{array}{r}\text { Total yearly } \\
\text { rainfed loss } \\
\text { (million } € \text { ) }\end{array}$ \\
\hline \multirow{7}{*}{1995} & Alava & Basque country & 3.79 & 27.87 & 1.86 & 0 & \multirow{7}{*}{64.84} & \multirow{7}{*}{104.47} \\
\hline & Navarre & Navarre & 0 & 0 & 12.13 & 116.06 & & \\
\hline & Lleida & Catalonia & 39.53 & 66.73 & 19.28 & 76.87 & & \\
\hline & La Rioja & La Rioja & 0 & 0 & 0 & 0 & & \\
\hline & Huesca & & 14.64 & 23.70 & 37.26 & 179.43 & & \\
\hline & Zaragoza & Aragon & 6.88 & 8.48 & 22.37 & 48.06 & & \\
\hline & Teruel & & 0 & 0 & 11.56 & 40.62 & & \\
\hline \multirow{7}{*}{2005} & Alava & Basque country & 0 & 0 & 1.94 & 0 & \multirow{7}{*}{96.40} & \multirow{7}{*}{112.62} \\
\hline & Navarre & Navarre & 0 & 0 & 4.10 & 0 & & \\
\hline & Lleida & Catalonia & 27.44 & 0 & 13.91 & 31.73 & & \\
\hline & La Rioja & La Rioja & 0.39 & 0 & 3.65 & 0 & & \\
\hline & Huesca & & 51.52 & 52.11 & 32.91 & 53.98 & & \\
\hline & Zaragoza & Aragon & 17.04 & 30.77 & 23.67 & 52.49 & & \\
\hline & Teruel & & 0 & 0 & 32.45 & 109.82 & & \\
\hline \multirow{7}{*}{2006} & Alava & Basque country & 3.42 & 0 & 9.90 & 0 & \multirow{7}{*}{49.64} & \multirow{7}{*}{49.20} \\
\hline & Navarre & Navarre & 0.07 & 0.25 & 0 & 0 & & \\
\hline & Lleida & Catalonia & 26.56 & 72.23 & 7.29 & 0 & & \\
\hline & La Rioja & La Rioja & 0 & 0 & 2.57 & 297.87 & & \\
\hline & Huesca & & 19.59 & 36.72 & 9.30 & 74.92 & & \\
\hline & Zaragoza & Aragon & 0 & 0 & 11.94 & 33.96 & & \\
\hline & Teruel & & 0 & 0 & 8.21 & 33.85 & & \\
\hline \multirow{7}{*}{2007} & Alava & Basque country & 0 & 0 & 0 & 0 & \multirow{7}{*}{29.25} & \multirow{7}{*}{0.00} \\
\hline & Navarre & Navarre & 0 & 0 & 0 & 0 & & \\
\hline & Lleida & Catalonia & 26.67 & 88.80 & 0 & 0 & & \\
\hline & La Rioja & La Rioja & 2.58 & 0 & 0 & 0 & & \\
\hline & Huesca & & 0 & 0 & 0 & 0 & & \\
\hline & Zaragoza & Aragon & 0 & 0 & 0 & 0 & & \\
\hline & Teruel & & 0 & 0 & 0 & 0 & & \\
\hline \multirow{7}{*}{2008} & Alava & Basque country & 0 & 0 & 0 & 0 & \multirow{7}{*}{1.09} & \multirow{7}{*}{0.00} \\
\hline & Navarre & Navarre & 0 & 0 & 0 & 0 & & \\
\hline & Lleida & Catalonia & 0 & 0 & 0 & 0 & & \\
\hline & La Rioja & La Rioja & 1.09 & 7.35 & 0 & 0 & & \\
\hline & Huesca & & 0 & 0 & 0 & 0 & & \\
\hline & Zaragoza & Aragon & 0 & 0 & 0 & 0 & & \\
\hline & Teruel & & 0 & 0 & 0 & 0 & & \\
\hline
\end{tabular}

Source: Authors' elaboration.

drought impacts to an high aggregated value indicator (GVA) results in a greater impact than the one calculated before, but obtained from a more precise causation chain, fitted statistically.

The evolution of agri-food industrial GVA also depends on other factors unrelated to agricultural inputs and to water availability. Thus, to generalize the procedure for all provinces there is no validity without a thorough review before being implemented. For Catalonia at least, it was not correct for rainfed.

The other variable affected indirectly by drought, and analysed here, is agricultural employment. It is the only variable not analysed on economic terms but, rather, the impact is measured in terms of the number of jobs. Pérez y Pérez and Barreiro-Hurlé (2009) estimate a total employment loss due to drought of 11275 jobs, and losses directly related to agriculture, forestry and fisheries of 8094 jobs. However, results from our econometric models, using official employment monthly statistics, reveal that there were no significant impacts on employment. On the one hand, farm family employment shows a clear and long-sustained decreasing trend as a result of structural change. Table 3 shows the significance of irrigation with negative sign, which is a proxy variable for the trend followed. On the other hand, hired labour shows no pattern of evolution with erratic and small variations unrelated to water availability. This may be due to the fact that seasonal, informal or family labour changes are not recorded accurately in social security statistics. 
Table 6. 2005-2006 spread of impacts: percentages of reduction in water availability, impacts transmitted through elasticity on production values and on GVA (at autonomous community level only). Final indirect impacts (million $€$ ) on Agri-industry.

\begin{tabular}{|c|c|c|c|c|c|c|c|c|c|}
\hline & \multicolumn{5}{|c|}{ Irrigation effects } & \multicolumn{4}{|c|}{ Rainfed effects } \\
\hline & $\begin{array}{r}\text { Autonomous } \\
\text { community }\end{array}$ & $\begin{array}{r}\Delta \mathrm{Wa} 1 \\
(\%)\end{array}$ & $\begin{array}{r}\text { IMPACT ON } \\
\operatorname{IPV}(\%)^{1}\end{array}$ & $\begin{array}{r}\text { IMPACT GVA } \\
\mathrm{Wa}_{1}(\%)^{2}\end{array}$ & $\begin{array}{r}\text { IMPACT GVA } \\
\text { Wa1 (MILLION } € \text { ) }\end{array}$ & $\begin{array}{r}\Delta \mathrm{Wa} 2 \\
(\%)\end{array}$ & $\begin{array}{r}\text { IMPACT ON RPV } \\
(\%)^{3}\end{array}$ & $\begin{array}{r}\text { IMPACT GVA } \\
\mathrm{Wa}_{2}(\%)^{4}\end{array}$ & $\begin{array}{r}\text { IMPACT GVA } \\
\text { Wa2 (MILLION } € \text { ) }\end{array}$ \\
\hline \multicolumn{10}{|c|}{ Year 1995} \\
\hline Alava & B. Country 5 & 34.51 & 2.42 & 2.52 & 46.96 & - & - & - & - \\
\hline Lleida & Catalonia & - & - & - & - & 27.69 & 7.17 & 3.68 & 49.73 \\
\hline La Rioja & La Rioja & 97.80 & 0.19 & 0.30 & 37.75 & 68.18 & 18.06 & - & - \\
\hline Navarre & Navarre & 33.89 & -0.31 & - & - & 26.87 & -0.61 & - & - \\
\hline Huesca & Aragon & 28.41 & 2.63 & 3.89 & & 48.09 & 25.09 & - & \\
\hline Teruel & & 13.73 & 3.38 & 5.01 & 73.11 & 52.02 & 17.48 & - & - \\
\hline Zaragoza & & 98.07 & -4.27 & - & & 25.26 & 12.46 & - & \\
\hline \multicolumn{10}{|c|}{ Year 2005} \\
\hline Alava & B. Country ${ }^{5}$ & - & - & - & - & 0.32 & 0.04 & - & - \\
\hline Lleida & Catalonia & - & - & - & - & 13.34 & 3.46 & 1.77 & 42.14 \\
\hline La Rioja & La Rioja & 69.42 & 0.14 & 0.21 & 42.66 & 53.88 & 14.27 & - & - \\
\hline Navarre & Navarre & - & - & - & - & 45.65 & -1.04 & - & - \\
\hline Huesca & Aragon & 97.73 & 9.04 & 13.39 & & 42.04 & 21.94 & - & \\
\hline Teruel & & 34.03 & 8.38 & 12.42 & 367.59 & 24.60 & 8.27 & - & - \\
\hline Zaragoza & & 71.06 & -3.09 & - & & 51.42 & 25.36 & - & \\
\hline \multicolumn{10}{|c|}{ Year 2006} \\
\hline Alava & B. Country ${ }^{5}$ & 31.07 & 2.18 & 2.27 & 78.81 & 18.73 & 2.34 & - & - \\
\hline Lleida & Catalonia & 1.02 & 0.02 & 0.02 & 0.55 & - & - & - & - \\
\hline La Rioja & La Rioja & 67.20 & 0.13 & 0.21 & 42.75 & 51.57 & 13.66 & - & - \\
\hline Navarre & Navarre & 3.71 & -0.03 & - & - & - & - & - & - \\
\hline Huesca & Aragon & 38.02 & 3.52 & 5.21 & & - & - & - & \\
\hline Teruel & & - & - & - & 147.51 & 10.05 & 3.38 & - & - \\
\hline Zaragoza & & 64.20 & -2.79 & - & & - & - & - & \\
\hline
\end{tabular}

(1) Direct impact on irrigation production value produced by $\zeta_{i}$. (2) Indirect impact on agri-food industry GVA produced by $\zeta_{i} \beta_{i}$. (3) Direct impact on rainfed production produced by $\mu_{i}$. (4) Indirect impact on agri-food industry GVA produced by $\gamma_{i} \mu_{i}$.

\section{Conclusions}

Drought is a natural hazard that affects many sectors, but agriculture is particularly vulnerable. Therefore, the analysis of these impacts is important when defining effective drought management and mitigation strategies. An accurate assessment of socioeconomic drought impacts, along with the development of a simple methodology that can be replicated in other river basins, may be a useful contribution to the field of natural hazard economics.

The econometric models formulated and fitted in this paper showed mixed results. In some provinces of the Ebro Basin, water availability (precipitation or drought indices) provided a statistically significant explanation of the variation in agricultural economic output. These are the provinces with more surface devoted to extensive annual crops (cereals, forage), while in those provinces where where fruit trees (Lleida) or wine grapes (Álava and Rioja) predominate, output is more dependent on the variation of product prices and quality. However, trends are found to be crucial in explaining economic output in both rainfed and irrigated production. Drought impacts have to be measured around trends to avoid serious miscalculations. This is one of the disadvantages of using IO or CGE models, and one the advantages of our approach. We leave to subsequent work the use of non-linear (quadratic or exponential) trends, instead of a linear trend.

Unlike other studies, our analysis develops a complete framework by considering direct and indirect impacts. As indirect impacts have been considered, some assertions can be made: (i) indirect impacts are more related to direct impacts of drought impacts than to water scarcity, indeed they result from impact transmission processes; (ii) while indirect impacts can be compensated in the macro level by market fluctuations or trends, they are far greater than the direct effects in absolute terms; (iii) agri-food industry is closely related to the results of irrigation production, and probably to commodity price shocks; and (iv) agricultural employment, at least formally hired labour, is hardly affected by water scarcity, though informal, family or seasonal labour might have been impacted. The main policy implication of our findings is that focusing only on direct impacts in agriculture leaves out a significant part of the drought costs from the focus of governments' attention.

Our two-level approach provides empirical measurements of impacts along the value chain and employment. Chained elasticities can measure the existing relation between water scarcity and the economic output of different sectors, especially if the sector is directly dependent on agricultural outputs. This procedure allows for a vision of the magnitude of 
the impact of a reduction in water availability in the macro level. Elasticities also reveal the importance of drought impacts according to the economic importance of each measured variable. This importance diminishes as we approach the macroeconomic indicators from those directly dependent on water abstractions and precipitation, but in absolute economic terms the largest impacts were found in agri-food industry GVA.

This methodology can be applicable to other regions by developing similar econometric models, but the specific reality of each region must be taken into account to elucidate if the impacts are attributable to water scarcity. This is because there might be other trends acting independently of drought periods.

The importance of having accurate information is relevant for policy makers and water users. These results suggest that more open agricultural markets, and wider and more flexible procurement strategies of the agri-food industry reduce the socio-economic exposure to drought cycles.

Acknowledgements. This paper presents the results of research conducted under PREEMPT project (Policy relevant assessment of the socioeconomic effects of droughts and floods, ECHO - grant agreement \# 070401/2010/579119/SUB/C4), which constitutes an effort to provide a comprehensive assessment of the socioeconomic impacts of the 2004-2008 drought in the Ebro River basin, Spain.

Edited by: H. Kreibich

Reviewed by: two anonymous referees

\section{References}

AEMET: Rainfall data series 1995-2009, 2009.

Alcalá Agulló, F. and Sancho Portero, I.: Agua y producción agrícola: un análisis econométrico del caso de Murcia, Revista española de estudios agrosociales y pesqueros, 197, 129-158, 2002 (in Spanish).

Berrittella, M., Hoekstra, A. Y., Rehdanz, K., Roson, R., and Tol, R. S. J.: The economic impact of restricted water supply: A computable general equilibrium analysis, Water Res., 41, 1799-1813, 2007.

Booker, J. F., Michelsen, A. M., and Ward, F. A.: Economic impact of alternative policy responses to prolonged and severe drought in the Rio Grande Basin, Water Resour. Res., 41, W02026, doi:10.1029/2004WR003486, 2005.

Carroll, N., Frijters, P., and Shields, M. A.: Quantifying the Costs of Drought: New Evidence from Life Satisfaction Data, J. Population Econom., 22, 445-461, 2009.

CHE (Confederación Hidrográfica del Ebro): Borrador del Plan Hidrológico del Ebro, 2011 (in Spanish).

CHE-SDMP (Confederación Hidrográfica del Ebro): Ebro Special Drought Management Plan, 2007 (in Spanish).

Chóliz, J. S., Bielsa, J., and Cazcarro, I.: La agricultura y el agua en el sistema productivo, Análisis de su importancia en la economía aragonesa a través de una Matriz de Contabilidad Social, 2009 (in Spanish).
Decaluwe, B., Patry, A., and Savard, L.: When water is no longer heaven sent: Comparative pricing analysis in a AGE model, Cahiers de travail, 99, 1-39, 1999.

Ding, Y., Hayes, M., and Widhalm, M. M.: Measuring Economic Impacts of Drought: A Review and Discussion, Disaster Prevent. Manage., 20, 343-446, 2011.

Dono, G. and Mazzapicchio, G.: Uncertain water supply in an irrigated Mediterranean area: An analysis of the possible economic impact of climate change on the farm sector, Agr. Systems, 103, 361-370, 2010.

Estrela, T. and Vargas, E.: Drought Management Plans in the European Union, The Case of Spain, Water Resour. Manage., 26, 1537-1553, doi:10.1007/s11269-011-9971-2, 2012.

Frey, B. S., Luechinger, S., and Stutzer, A.: The life satisfaction approach to environmental valuation, Universität München, IfoInstitut für Wirtschaftsforschung, CESifo, IZA, 2009.

Garrido, A., Gil, M., and Gómez-Ramos, A.: Disentangling the social, macro and microeconomic effects of agricultural droughts: An application to Spanish irrigated agriculture, in: Options Mediterranéenes and CIHEAM, Economics of Drought and Drought Preparednesss in a Climate Change Context, 2010.

Gil, M., Garrido, A., and Gomez-Ramos, A.: Economic analysis of drought risk: An application for irrigated agriculture in Spain, Agr. Water Manage., 98, 823-833, 2011.

Gil-Sevilla, M., Garrido, A., and Gomez-Ramos, A.: How to link agricultural productivity, water availability and water demand in a risk context: a model for managing hydrological risks, Spanish J. Agr. Res., 8, 207-220, 2010.

Gómez, C. M., Tirado, D., and Rey-Maquieira, J.: Water exchange versus water work: Insights from a computable general equilibrium model for the Balearic Islands, Water Resour. Res., 42, W10502, doi:10.1029/2004WR003235, 2004.

Goodman, D. J.: More reservoirs or transfers? A computable general equilibrium analysis of projected water shortages in the Arkansas River Basin, J. Agr. Resource Econom., 25, 698-713, 2000.

Hartmann, T., Di Bella, C., and Oricchio, P.: Assessment of the possible drought impact on farm production in the SE of the province of Buenos Aires, Argentina* 1, ISPRS J. Photogram. Remote Sens., 57, 281-288, 2003.

Iglesias, A., Cancelliere, D., Gabiña, D., López-Francos, A., Moneo, M., and Rossi, G. (Eds.): Medroplan drought management guidelines, 2007.

Jenkins, M. W., Lund, J. R., and Howitt, R. E.: Economic losses for urban water scarcity in California, J. Am. Water Works Association, 95, 58-70, 2003.

Klein, K. K. and Kulshreshtha, S. N.: Economic impacts of small-scale irrigation under drought conditions in northwestern saskatchewan: An application of the agricultural drought impact evaluation model, Agr. Syst., 30, 205-215, 1989.

Leontief, W.: Input-output economics. Oxford University Press, USA, 1986.

Logar, I. and van der Berg, J.: Methods to assess costs of drought damages and policies for drought mitigation and adaptation: Review and recommendations, Water Resour. Manage., 27, 17071720, 2013.

Lorite, I., Mateos, L., Orgaz, F., and Fereres, E.: Assessing deficit irrigation strategies at the level of an irrigation district, Agr. Water Manage., 91, 51-60, 2007. 
MAGRAMA: Hydrological Bulletins, available at: http://eportal. magrama.gob.es/BoleHWeb/, last access: August 2013, 2012.

MAGRAMA: Agricultural Statistics Yearbooks, available at: http://www.magrama.gob.es/es/estadistica/temas/ estad-publicaciones/anuario-de-estadistica/ (Last access: 2011), 1995-2009.

Martínez-Cachá, A. (Ed.): Impacto económico de las sequías en el sureste agrario español., 187 pp., 2004 (in Spanish).

Martin-Ortega, J. and Berbel, J.: Using multi-criteria analysis to explore non-market monetary values of water quality changes in the context of the Water Framework Directive, Sci. Total Environ., 408, 3990-3997, 2010.

Martin-Ortega, J., González-Eguino, M., and Markandya, A.: The costs of drought: the 2007/2008 case of Barcelona, Water Policy, 14, 539-560, 2012.

Morilla, C. R., Diaz-Salazar, G. L., and Cardenete, M. A.: Economic and environmental efficiency using a social accounting matrix, Ecol. Economi., 60, 774-786, 2007.

Peck, D. E. and Adams, R. M.: Farm-level impacts of prolonged drought: is a multiyear event more than the sum of its parts? Aust. J. Agr. Resour. Econom., 54, 43-60, 2010.

Pérez y Pérez, L. and Barreiro-Hurlé, J.: Assessing the socioeconomic impacts of drought in the Ebro River Basin, Spanish J. Agr. Res., 7, 269-280, 2009.

Quiroga, S. and Iglesias, A.: A comparison of the climate risks of cereal, citrus, grapevine and olive production in Spain, Agr. Syst., 101, 91-100, 2009.

Quiroga, S., Fernández-Haddad, Z., and Iglesias, A.: Crop yields response to water pressures in the Ebro basin in Spain: risk and water policy implications, Hydrol. Earth Syst. Sci., 15, 505-518, doi:10.5194/hess-15-505-2011, 2011.

Ritcher, G. M. and Semenov, M. A.: Modelling impacts of climate change on wheat yields in England and Wales: assessing drought risks, Agr. Syst., 84, 77-97, 2005.
Rubio Calvo, E., Abad, J., Gimeno, Y., García, M., and Oliva, C.: Repercusión de la Sequía en los Riegos del Alto Aragón, 2006 (in Spanish).

Schoengold, K., Sunding, D. L., and Moreno, G.: Price elasticity reconsidered: Panel estimation of an agricultural water demand function, Water Resour. Res., 42, W09411, doi:10.1029/2005WR004096, 2006.

Schuh, G. E.: An econometric investigation of the market for hired labor in agriculture, J. Farm Econom., 44, 307-321, 1962.

Solow, R. M.: A contribution to the theory of economic growth, Quart. J. Econom., 70, 65-94, 1956.

Ward, F. A. and Pulido-Velazquez, M.: Economic Costs of Sustaining Water Supplies: Findings from the Rio Grande, Water Resour. Manage., 26, 2883-2909, doi:10.1007/s11269-012-0055-8, 2012.

Wilhite, D. A. (Ed.): Drought Assessment, Management and Planning; Theory and Case Studies, 316 pp., 1993.

Wilhite, D. A. and Glantz, M. H.: Understanding: The drought phenomenon: The role of definitions, Water In., 10, 111-120, 1985.

Wilhite, D. A., Svoboda, M. D., and Hayes, M. J.: Understanding the complex impacts of drought: A key to enhancing drought mitigation and preparedness, Water Resour. Manage., 21, 763-774, 2007.

Wipfler, L., van Lanen, H., Ludwig, F., Tallaksen, M., Fleig, K., Niemeyer, S., Sauquet, E., and Ramos, M.: Extended Guidance Document on the Natural System \& Drought, Xerochore project Deliverable, 1, 2009.

Xerochore: An exercise to assess research needs and policy choices in areas of drought, EU Project, 2010.

Xiao-Jun, W., Jian-Yun, Z., Shahid, S., ElMahdi, A., Rui-Min, H., Zhen-Xin, B., and Ali, M.: Water resources management strategy for adaptation to droughts in China, Mitigation Adapt. Strat. Global Change, 17, 1-15, doi:10.1007/s11027-011-9352-4 2012. 